\title{
Balance of assimilative and dissimilative nitrogen processes in a diatom-rich tidal flat sediment
}

\author{
K. Dähnke ${ }^{1,2}$, A. Moneta ${ }^{1}$, B. Veuger ${ }^{1}$, K. Soetaert ${ }^{1}$, and J. J. Middelburg ${ }^{1,3}$ \\ ${ }^{1}$ Department of Ecosystem Studies, Royal Netherlands Institute for Sea Research (NIOZ), Yerseke, The Netherlands \\ ${ }^{2}$ Helmholtz-Zentrum Geesthacht, Centre for Materials and Coastal Research, Institute of Coastal Research, Geesthacht, \\ Germany \\ ${ }^{3}$ Department of Earth Sciences-Geochemistry, Faculty of Geosciences, Utrecht University, Utrecht, The Netherlands
}

Correspondence to: K. Dähnke (kirstin.daehnke@ hzg.de)

Received: 29 May 2012 - Published in Biogeosciences Discuss.: 14 June 2012

Revised: 13 September 2012 - Accepted: 24 September 2012 - Published: 22 October 2012

\begin{abstract}
Tidal flat sediments are subject to repetitive mixing and resuspension events. In a short-term $(24 \mathrm{~h}){ }^{15} \mathrm{~N}$ labelling experiment, we investigated reactive nitrogen cycling in a tidal flat sediment following an experimentally induced resuspension event. We focused on (a) the relative importance of assimilatory versus dissimilatory processes and (b) the role of benthic microalgae therein. ${ }^{15} \mathrm{~N}$-labelled substrate was added to homogenized sediment, and ${ }^{15} \mathrm{~N}$ was subsequently traced into sediment and dissolved inorganic nitrogen (DIN) pools. Integration of results in a $\mathrm{N}$-cycle model allowed us to quantify the proportion of major assimilatory and dissimilatory processes in the sediment.

Upon sediment disturbance, rates of dissimilatory processes like nitrification and denitrification were very high, but declined rapidly towards a steady state. Once this was reached, the balance between assimilation and dissimilation in this tidal mudflat was mainly dependent on the nitrogen source: nitrate was utilized almost exclusively dissimilatory via denitrification, whereas ammonium was rapidly assimilated, with about a quarter of this assimilation due to benthic microalgae (BMA). Benthic microalgae significantly affected the nitrogen recycling balance in sediments, because in the absence of BMA activity the recovering sediment turned from a net ammonium sink to a net source.

The driving mechanisms for assimilation or dissimilation accordingly appear to be ruled to a large extent by external physical forcing, with the entire system being capable of rapid shifts following environmental changes. Assimilatory pathways gain importance under stable conditions, with a substantial contribution of BMA to total assimilation.
\end{abstract}

\section{Introduction}

Nitrogen is a key element in aquatic ecosystems and humaninduced elevated inputs of nitrogen are a widespread problem that often results in reduced water quality in coastal regions. The ability of an ecosystem to deal with these increased inputs depends on its ability to remove the excess nitrogen. In coastal ecosystems, the sediment is an important component for uptake, transformation, and removal of reactive nitrogen. In such shallow regions, the sediment acts as an important filter for carbon and nitrogen, removing a large share of riverine nitrate via denitrification (Heip et al., 1995; Deek et al., 2011). Overall, sediments hold a key role in nitrogen cycling, as both oxic and anoxic processes can occur simultaneously and on very small spatial scales.

When nitrogen is released from organic matter in the form of ammonium it can enter a cascade of dissimilatory reactions (primarily nitrification and denitrification) in which the nitrogen compounds are converted to yield energy and which eventually leads to permanent loss of $\mathrm{N}$ from the sediment as $\mathrm{N}_{2}$ (e.g. Dalsgaard et al., 2005; Laursen and Seitzinger, 2002). Contrasting these dissimilatory reactions, ammonium and nitrate can also be assimilated by the benthic microbial community, supporting their nitrogen demand for growth (Blackburn, 1979; Blackburn and Henriksen, 1983). These assimilatory processes can retain anthropogenic nitrogen in coastal sediments so that sediments act as a temporary buffer for aquatic nutrient concentrations (Dähnke et al., 2010; van Beusekom et al., 1999). 
Therefore, a key feature of the sediment with respect to the removal of excess nitrogen is the balance between assimilatory and dissimilatory pathways. In this respect, benthic microalgae (BMA) play an important role in regulating sedimentary $\mathrm{N}$-cycling. Besides their own contribution in nitrogen assimilation, they can, in nitrogen-rich environments, increase nutrient fluxes to the sediment and the benthic heterotrophic community (Piehler et al., 2010, An and Joye, 2001). Competition for ammonium between BMA and the heterotrophic community can however limit nitrification rates under N-starved conditions (Risgaard-Petersen, 2003; Risgaard-Petersen et al., 2004). BMA can also stimulate the bacterial community via exudation of dissolved organic compounds (Middelboe et al., 1998). However, processing pathways of reactive nitrogen in sediments depend on various environmental parameters, such as particle mixing due to bioturbation or waves and current activity (Holstein and Wirtz, 2009). Yet, the balance of nitrogen assimilation versus dissimilation in coastal regions has often been merely studied in the water column (e.g. Lipschultz et al., 1986, Andersson et al., 2006b; Ward, 2005). In this study, we aimed for a combined assessment of the sedimentary processes, using an integrated experimental and modelling approach, to investigate this balance in tidal sediments from the eutrophic Scheldt estuary.

Our principal goal was to investigate the balance between assimilatory and dissimilatory processes in the benthic $\mathrm{N}$ cycle in sediments subject to repetitive resuspension events. In tidal systems such as the Scheldt estuary, particles in sediments are transported by waves, bioturbation and dredging (Chen et al., 2005), and this sediment reworking can have a large, though probably only short-term, impact on sediment nitrogen cycling (Trimmer et al., 2005). To unravel nitrogen cycling in sediments, and the potential role of different assimilative and dissimilative processes therein, stable isotope $\left({ }^{15} \mathrm{~N}\right)$ tracer studies have proven to be a valuable tool. Tracer applications require uniform distribution during incubations. We have therefore used homogenized sediments to ascertain homogenous distribution of tracer and to mimic repetitive sediment disturbance events. Homogenized sedimentwater mixtures have shown to provide a good approximation of relevant processes including potential canonical denitrification rates in marine and estuarine sediments (e.g. Dalsgaard and Thamdrup, 2002; Thamdrup and Dalsgaard, 2002; Trimmer et al., 2003), and of the relative contribution of the autotrophic versus heterotrophic community to N-cycling (e.g. Risgaard-Petersen et al., 2005; Veuger et al., 2005).

In this study, added ${ }^{15} \mathrm{~N}$ was traced into various particulate and dissolved N-pools, and integration of results by means of an N-cycle model allowed us to quantify rates for all major $\mathrm{N}$-cycling processes. Thereby we could assess the overall balance between assimilatory and dissimilatory processes in the sediments directly following and during recovery from a homogenization event.

\section{Materials and methods}

The Scheldt estuary (Fig. 1) is located in the SW Netherlands and Belgium. The catchment area is densely populated, and the system is highly eutrophic. The predominant form of reactive nitrogen in the river is in the form of nitrate, with nitrate concentrations of 44 to $67 \mu \mathrm{M}$ in the seaward part of the estuary up to 2002 (Soetaert et al., 2006). Passing tidal flats, the river discharges into the southern North Sea. Sediments in these tidal flats in the outer estuary are mixed due to bioturbation, waves and, most importantly, tidal forcing (Chen et al., 2005; Widdows et al., 2004), with a suspended matter transport rate of $\sim 0.7$ tons $\mathrm{m}^{-2}$ per tide (Chen et al., 2005). The tidal amplitude ranges from $3.8 \mathrm{~m}$ in the western to $5.2 \mathrm{~m}$ in the eastern part of the estuary (Andersson et al., 2006a).

\subsection{Sediment sampling}

In early October 2008, surface sediment was collected from an intertidal mudflat (Biezelingse Ham) in the brackish/marine section of the Scheldt estuary (The Netherlands). Surface sediment was sampled at low tide by carefully scraping off the oxic top layer of the sediment. 401 of site water were taken from nearby intertidal drains. In situ temperature of the water was $16^{\circ} \mathrm{C}$, and the salinity was 21.3 . Sediment and site water were returned to the lab within $1 \mathrm{~h}$, where the sediment was sieved (mesh size $1 \mathrm{~mm}$ ) to remove larger fauna. The sediment was left to settle overnight at $17^{\circ} \mathrm{C}$ before the slurries were prepared.

\subsection{Sediment incubations}

For the slurry preparation, overlying water was decanted, and $50 \mathrm{ml}$ of the remaining sediment were aliquoted into $250 \mathrm{ml}$ glass bottles during continuous stirring. Site water was added to the bottles to a total volume of approximately $200 \mathrm{ml}$. Half the bottles were amended with $0.6 \mu \mathrm{mol}{ }^{15} \mathrm{NH}_{4}^{+}$(added as ${ }^{15}\left(\mathrm{NH}_{4}\right)_{2} \mathrm{SO}_{4}\left(\right.$ Sigma, 98 at $\left.\%{ }^{15} \mathrm{~N}\right)$ ); the other half was labelled with $0.6 \mu \mathrm{mol} \mathrm{Na}{ }^{15} \mathrm{NO}_{3}$ (Sigma, 98 at $\%{ }^{15} \mathrm{~N}$ ). To ensure identical starting conditions and nutrient concentrations in the different ${ }^{15} \mathrm{~N}$-treatments, the same amounts of unlabelled $\mathrm{NH}_{4}^{+}$and $\mathrm{NO}_{3}^{-}$were added to the ${ }^{15} \mathrm{NO}_{3}^{-}$and ${ }^{15} \mathrm{NH}_{4}^{+}$ treatments respectively. After nutrient and label additions, bottles were shaken to ensure homogeneous distribution of the added substrates. Final labelling percentage in the sediment slurries was 4.7 at $\%{ }^{15} \mathrm{~N}$ for the ${ }^{15} \mathrm{~N}$-nitrate additions and 4.5 at $\%{ }^{15} \mathrm{~N}$ for the ${ }^{15} \mathrm{~N}$-ammonium additions, meaning that both compounds were added at tracer level. Incubation bottles were kept at $17^{\circ} \mathrm{C}$ with open caps to enable free gas exchange. To capture a maximal range of algal activity, parallel batches of slurry bottles were incubated in dark and light. Incubations were performed for 0.1, 0.5, 1, 3, 6 and $24 \mathrm{~h}$. At the respective incubation time points, two replicate bottles from each treatment were homogenized to ensure equal nutrient and label distribution, followed by freezing in liquid 


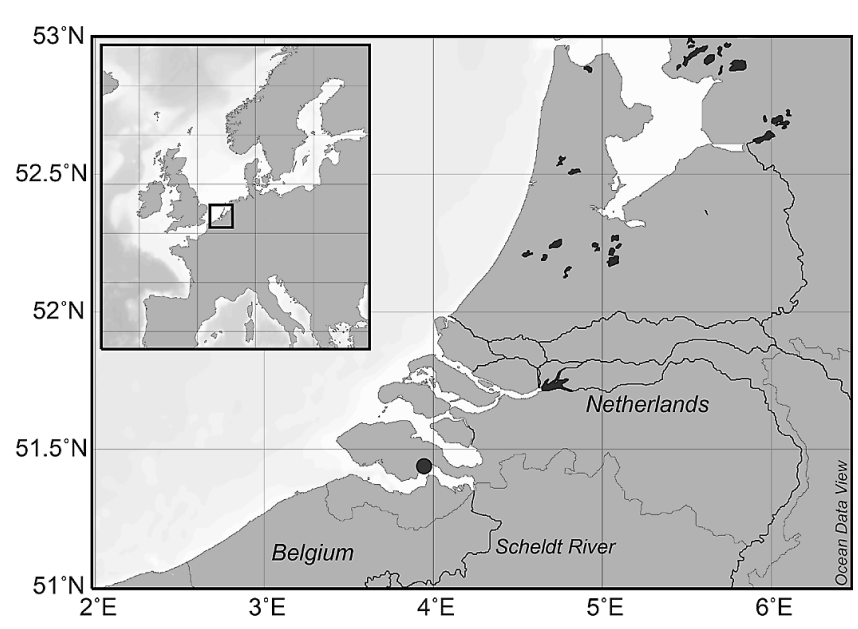

Fig. 1. Map of the study area. Black circle indicates sampling site.

$\mathrm{N}_{2}$ to stop microbiological activity. The bottles were then kept frozen at $-18^{\circ} \mathrm{C}$ until further processing. Natural, unlabelled sediment and water were sampled for analysis of natural abundance of ${ }^{15} \mathrm{~N}$ in the various pools analyzed for ${ }^{15} \mathrm{~N}$ content (see below).

\subsection{Extraction procedures}

Upon thawing, samples were split into a solid fraction (sediment) and a water fraction (mixture of pore water and overlying water); the total slurry volume was homogenized and then centrifuged $\left(1500 \mathrm{~g}, 15^{\prime}\right)$. The supernatant was decanted, filtered (GF-D, combusted at $450{ }^{\circ} \mathrm{C}$ for $4 \mathrm{~h}$ ), and frozen for later analysis of concentrations of $\mathrm{NH}_{4}^{+}, \mathrm{NO}_{2}^{-}$ and $\mathrm{NO}_{3}^{-}$and isotope composition of $\mathrm{NH}_{4}^{+}$and $\mathrm{NO}_{3}^{-}+\mathrm{NO}_{2}^{-}$. Concentrations of ammonium, nitrite and nitrate were measured with standard colorimetric techniques (Grasshoff and Anderson, 1999) in an automated flow-through system.

To distinguish the ${ }^{15} \mathrm{~N}$ in organic matter from ammonium that was bound to sediment particles, a subsample of sediment was transferred to a $2 \mathrm{M} \mathrm{KCl}$ solution, shaken vigorously and then centrifuged $\left(1500 \mathrm{~g}, 15^{\prime}\right)$ (Rich et al., 2008). The supernatant was removed, and the pellet was washed three times with Milli-Q water before the sediment was freeze-dried for later isotope analysis.

${ }^{15} \mathrm{~N}$ incorporated into the $\mathrm{KCl}$-extracted sediment is assumed to represent ${ }^{15} \mathrm{~N}$ assimilation into organic matter while ${ }^{15} \mathrm{~N}$ in the untreated bulk sediment also includes $\mathrm{KCl}-$ extractable ${ }^{15} \mathrm{~N}$ (including sediment-bound ${ }^{15} \mathrm{NH}_{4}^{+}$). The latter will be presented as the difference between ${ }^{15} \mathrm{~N}$ in untreated versus $\mathrm{KCl}$-extracted sediment.

\section{$2.4{ }^{15} \mathrm{~N}$ analyses}

\subsubsection{Nitrate and nitrite}

${ }^{15} \mathrm{~N}$ enrichment of nitrite and nitrate was measured by the indophenol extraction method based on Preston et al. (1998). When referring to labelled ${ }^{15} \mathrm{NO}_{3}^{-}$in the following, this accordingly includes nitrite. In a first step, the sample nitrate was reduced to nitrite using cadmium granules. To ensure sufficient reduction of nitrate, $5 \mathrm{ml}$ of sample, containing $0.2 \mathrm{~g}$ of cadmium, were buffered with an ammonium chloride/hydroxide buffer to a pH of 8.5 (Jones, 1984). Samples were then left to react for $3 \mathrm{~h}$ at room temperature on a horizontal shaker at $130 \mathrm{rpm}$. This step was followed by isotope analysis of nitrate and nitrite as described in detail by Preston et al. (1998). In brief, nitrite was converted to the colour complex Sudan-I by diazotization with 2-naphthol and aniline sulfate. The colour complex was concentrated on a C-18 extraction column, eluted with ethylacetate and derivatized for GC analysis using MTBSTFA (N-(t-butyldimethylsilyl)$\mathrm{N}$-methyltrifluoroacetamide). Derivatized samples were analyzed by gas chromatography-mass spectrometry (GC-MS) on a Thermo Finnigan Voyager quadrupole mass spectrometer using selected ion monitoring of $m / z 305.2$ and 306.2. The ratio of these two masses was used to determine the at $\%{ }^{15} \mathrm{~N}$ of the samples by comparison with standards of different ${ }^{15} \mathrm{~N}$ enrichment levels $\left(0.3\right.$ to 10 at $\left.\%{ }^{15} \mathrm{~N}\right)$.

\subsubsection{Ammonium}

${ }^{15} \mathrm{~N}$ enrichment of ammonium was measured by the ammonia diffusion method (Holmes et al., 1998; Sigman et al., 1997). Before use, glassware used was soaked in $1 \mathrm{M} \mathrm{HCl}$ over night and rinsed thoroughly with Milli- $\mathrm{Q}$ water; the chemicals and filters were combusted at $450{ }^{\circ} \mathrm{C}$ for $4 \mathrm{~h}$.

Different sample volumes, corresponding to $15 \mu \mathrm{g}$ of $\mathrm{NH}_{4}^{+}$-N, were aliquoted in $100 \mathrm{ml}$ screw cap bottles (Schott Duran), followed by addition of $\mathrm{NaCl}$ solution $\left(50 \mathrm{gl}^{-1}\right)$ to achieve a final salinity of approx. $35 \mathrm{~g}^{-1}$ and a final volume of $90 \mathrm{ml}$. After addition of an ammonia trap (consisting of an acidified GF/D filter sealed between two Teflon membranes) and $0.27 \mathrm{~g}$ of $\mathrm{MgO}$ per bottle, the bottles were immediately closed tightly and incubated at room temperature on a shaker table $(60 \mathrm{rpm})$ for 14 days. Thereafter, filter packs were dried and filters were placed in tin capsules and analyzed for their ${ }^{15} \mathrm{~N} /{ }^{14} \mathrm{~N}$ ratios on an elemental analyzer coupled to an isotope ratio mass spectrometer (EA-IRMS, Thermo Delta V).

\subsubsection{Sediment samples}

${ }^{15} \mathrm{~N}$ enrichment of freeze-dried samples of untreated bulk sediment and of $\mathrm{KCl}$-extracted sediment was analyzed on an elemental analyzer coupled to an isotope ratio mass spectrometer (EA-IRMS, Thermo Delta V). All data were referenced to international standard material (IAEA N2) and an 
internal standard; the standard deviation for standards and replicate analysis was better than $0.2 \%$.

\subsubsection{Calculations}

Stable isotope results will be presented as concentration excess ${ }^{15} \mathrm{~N}$ per bottle, which were calculated as follows: concentration excess ${ }^{15} \mathrm{~N}=\left[\left(\right.\right.$ at $\%{ }^{15} \mathrm{~N}_{\text {sample }}$ - at $\left.\left.\%{ }^{15} \mathrm{~N}_{\text {control }}\right) / 100\right] \times$ [concentration $\mathrm{N}$ in sample]. At $\%{ }^{15} \mathrm{~N}$ was calculated from $\delta^{15} \mathrm{~N}$ as

$$
\begin{aligned}
\text { at } \%{ }^{15} \mathrm{~N}= & {\left[100 \times R_{\text {standard }} \times\left(\delta^{15} \mathrm{~N}_{\text {sample }} / 1000\right)+1\right] / } \\
& {\left[1+R_{\text {standard }} \times\left(\delta^{15} \mathrm{~N}_{\text {sample }} / 1000\right)+1\right] }
\end{aligned}
$$

and $\delta^{15} \mathrm{~N}$ was calculated as

$\delta^{15} \mathrm{~N}(\% \circ)=\left[\left(R_{\text {sample }} / R_{\text {standard })}-1\right] \times 1000\right.$.

where $R={ }^{15} \mathrm{~N} /{ }^{14} \mathrm{~N}$ and $R_{\text {standard }}=0.003677$. To correct for ambient ${ }^{15} \mathrm{~N}$, unlabelled sediment or water were used as controls. For an easier comparison of ${ }^{15} \mathrm{~N}$ in particulate and dissolved pools, excess label is expressed as total $n m o l{ }^{15} \mathrm{~N}$ per bottle.

\subsection{Modelling of process rates}

To unravel the complex fluxes of nitrogen in the sediment incubations, the experimental data were incorporated into a zero-dimensional $\mathrm{N}$-cycle model. A schematic of the relevant reactions in the model is shown in Fig. 2; the reaction kinetics and a detailed description of the model can be found in the supplementary material.

In a 0-D model, processes can occur simultaneously, and there is no vertical resolution, which resembles the conditions in the homogenized slurries, where oxic and anoxic processes will occur simultaneously despite varying diffusion gradients. The relevant biogeochemical reactions that were taken into account in the final version of the model were incorporation of nitrate and ammonium into biomass, mineralization of organic matter (including heterotrophic denitrification), bulk $\mathrm{N}_{2}$ production, nitrification, dissimilatory nitrate reduction to ammonium (DNRA), storage of nitrate in diatom cells and physical ad- and desorption processes of ammonium to sediment particles (see Fig. 2). Furthermore, the model was based on the following assumptions:

1. There is no stable isotope fractionation during biological processing over time.

2. Due to the short incubation time, there is no recycling of ${ }^{15} \mathrm{~N}$-labelled organic matter to the ammonium pool. Overall mineralization of ${ }^{14} \mathrm{~N}$ organic matter depends on two pools of decaying detritus: one rapidly decomposing fraction and one that decomposes slowly. The former pool represents easily accessible organic matter.

The same process formulations, using the same parameter values, were used to describe the four different experimental

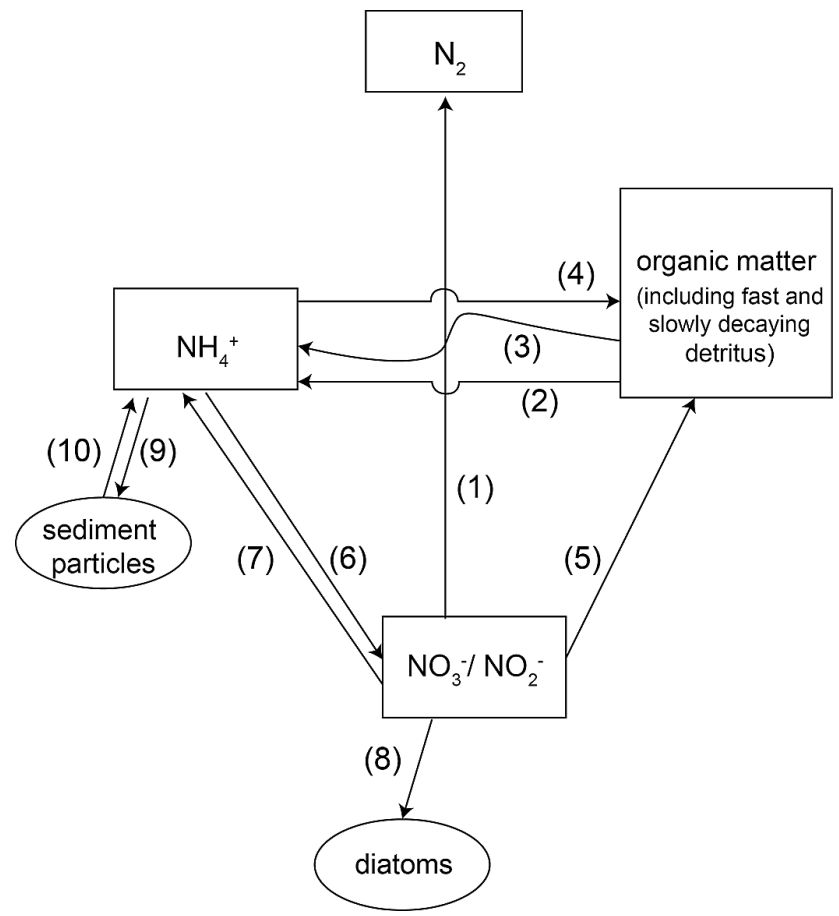

Fig. 2. Conceptual diagram of $\mathrm{N}$ fluxes in the $\mathrm{N}$-cycle model. Turnover processes: (1) denitrification; (2) oxic and anoxic mineralization; (3) mineralization coupled to denitrification; (4) ammonium assimilation; (5) nitrate assimilation; (6) nitrification; (7) DNRA; (8) nitrate storage in diatoms; (9) ammonium adsorption to particles, (10) desorption of ammonium from particles. Processes 8, 9 and 10 specifically apply to ${ }^{15} \mathrm{~N}$-labelled pools (see Sect. 2.5 for details).

conditions $\left(\mathrm{NO}_{3}^{-} / \mathrm{NH}_{4}^{+}\right.$addition versus dark/light). To improve the model fit, a process reacting differentially on the two isotope species of $\mathrm{NO}_{3}^{-}+\mathrm{NO}_{2}^{-}$needed to be included, in this case preferentially reacting on heavy isotopes. While such preferential turnover of heavy isotopes is not expected for the majority of biological pathways - a basic assumption of labelling studies - any process driven by diffusion (including ion-exchange between pore-water, sediment and biota) will preferentially sequester heavy isotopes upon addition of a labelled substrate until isotopic equilibrium is achieved. Hence, removal rates for the heavier isotope are expected to be fast at the beginning of the experiment, until equilibrium is reached.

The model reflects the different conditions in light and dark incubations by toggling on and off MPB assimilation. The slurries were prepared in light and thus treated equally in the beginning, so initial rates should be identical for dark and light incubations, assuming changes will occur with or some time after the change of light conditions. Light conditions should primarily affect nutrient uptake by BMA; effects on heterotrophic uptake should be less pronounced. We furthermore assume that dissimilatory reaction rates will remain constant in the dark. 


\section{Results}

\subsection{Dissolved inorganic nitrogen concentrations}

The total concentration of dissolved inorganic nitrogen (DIN) decreased in both light and dark incubations (Fig. 3). This decrease was most pronounced in the light incubations, where total DIN had decreased by $51 \%$ after one day. An initial drop in ammonium concentrations coincided with increasing nitrite concentration. Barring a DIN maximum after $6 \mathrm{~h}$, concentrations of all 3 inorganic nitrogen species dropped to final values of $27,0.8$ and $12 \mu \mathrm{M}$ for ammonium, nitrite and nitrate, respectively.

Up to $3 \mathrm{~h}$ after the start of the experiment, the dark nutrient concentrations were roughly comparable to those measured in light. After this time, the most pronounced difference was a steady increase in ammonium concentrations from $35 \mu \mathrm{M}$ after $1 \mathrm{~h}$ to $53 \mu \mathrm{M}$ after $24 \mathrm{~h}$ in the dark, whereas nitrite and nitrate concentration was comparable in light and dark incubations over the course of the entire incubation.

\section{2 ${ }^{15} \mathrm{~N}$ in $\mathrm{NO}_{3}^{-}$and $\mathrm{NH}_{4}^{+}$}

The label distribution in light or dark incubations was comparable for up to $3 \mathrm{~h}$. Absolute values of measured ${ }^{15} \mathrm{~N}$-excess in the various pools and model fits are shown in Fig. 4. The relative percentage of the label distribution in different pools during the incubation time is outlined in Fig. 5.

\subsection{1 ${ }^{15} \mathrm{~N}$-nitrate additions}

In the ${ }^{15} \mathrm{NO}_{3}^{-}$incubations, the majority of added label was not recovered in the dissolved pool, and we only found a slight ${ }^{15} \mathrm{~N}$ increase in ammonium and organic matter. For the sediment compartment, the increase corresponded in only a small $\Delta \delta^{15} \mathrm{~N}$ of $\sim 3 \%$, and is thus subject to some uncertainty. Nevertheless, standard deviations for replicate $\delta^{15} \mathrm{~N}$ measurements were usually better than $0.3 \%$, and indicate that the data are reasonably robust. Over the course of the entire experiment, a large part of the added label (i.e. the sum of all ${ }^{15} \mathrm{~N}$ recovered after $0.1 \mathrm{~h}$ ) disappeared. Only a small fraction $(\sim 8.0 \%$ after $24 \mathrm{~h})$ of ${ }^{15} \mathrm{~N}$ was found in ammonium or organic matter, and the main transfer of label to these pools occurred within the first hours of the incubation, when ${ }^{15} \mathrm{~N}$ in $\mathrm{KCl}$-extracted sediment (representing assimilation into organic matter) peaked, and ${ }^{15} \mathrm{~N}$ in ammonium rose to 7.3 and $7.4 \mu \mathrm{mol}$ per incubation bottle in light and dark, respectively (Figs. 4 and 5). Overall, the comparison of light vs. dark incubations showed only little differences in nitrate incorporation into organic matter or reduction of ${ }^{15} \mathrm{NO}_{3}^{-}$to ammonium, while the ${ }^{15} \mathrm{NO}_{3}^{-}$pool decreased slightly faster in light than in dark incubations (Fig. 5). Still, the final amount of missing ${ }^{15} \mathrm{NO}_{3}^{-}$in the budget was roughly comparable, $77 \%$ and $72 \%$ in dark and light, respectively. The label distributions for these pools show good agreement with the model results, verifying the underlying assumptions (Fig. 4).

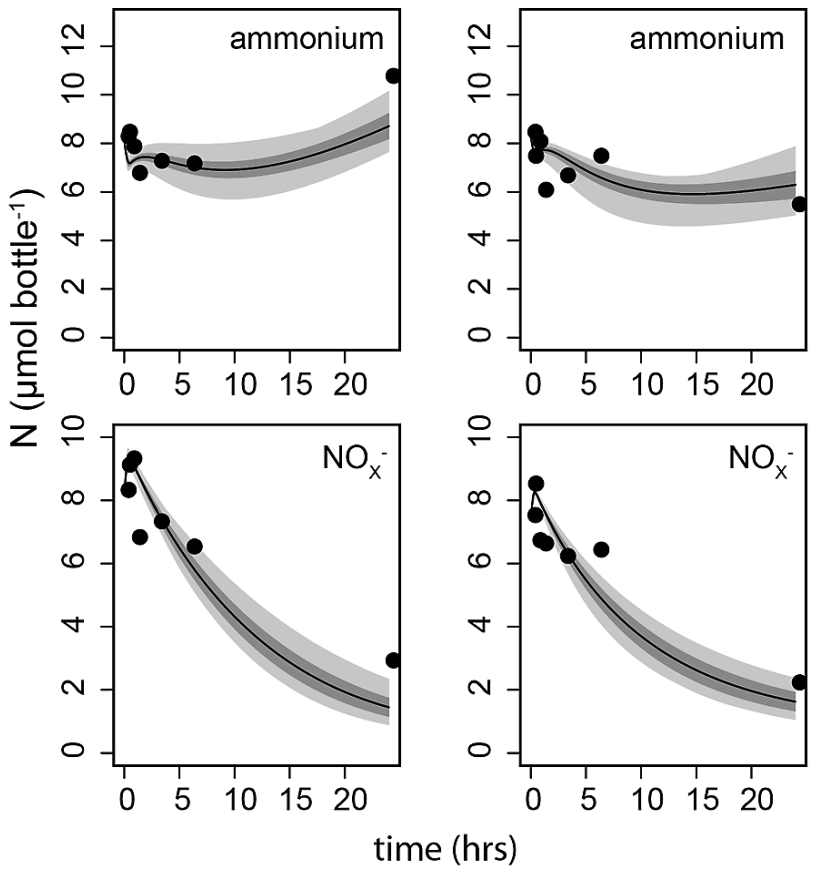

Fig. 3. Data and model fits for concentrations of ammonium and nitrate in dark (left side) and light (right side). The dark shaded area of the modelled curve represents one standard deviation; light shading indicates minimum and maximum values.

\subsection{2 $\quad{ }^{15} \mathrm{~N}$-ammonium additions}

The ${ }^{15} \mathrm{~N}$ in the ammonium additions was mostly recovered in the sediment over the course of the experiment; only minor amounts of label were recovered in oxidized nitrogen components. In both light and dark, ${ }^{15} \mathrm{NH}_{4}^{+}$was rapidly removed from the dissolved pool, with only $21 \%$ and less than $4 \%$ remaining in the free ammonium pool after $24 \mathrm{~h}$ of dark and light incubations, respectively (Figs. 4 and 5). Initially, a considerable fraction of the label was transferred to the $\mathrm{NO}_{3}^{-}$pool, with a peak of $\sim 65 \mathrm{nmol}$ excess ${ }^{15} \mathrm{~N}$ after $0.5 \mathrm{~h}$ (Fig. 4b). In both the light and dark incubations, the portion of labelled ${ }^{15} \mathrm{NO}_{3}^{-}$then decreased, dwindling at the detection limit after $24 \mathrm{~h}$.

A large fraction of labelled ammonium rapidly appeared in the $\mathrm{KCl}$-extractable pool representing particle-bound ammonium (Figs. 4 and 5). After an initial peak a few minutes after slurry preparation (Fig. 4b), the ${ }^{15} \mathrm{~N}$ excess in this pool remained rather stable at around $20 \%$ of the total label addition. In the non-extractable nitrogen pool (assumed to be a good approximation of ${ }^{15} \mathrm{~N}$ assimilated into organic matter), excess ${ }^{15} \mathrm{~N}$ increased steadily, containing $56 \%$ and $34 \%$ after $24 \mathrm{~h}$ in light and dark, respectively.

Figure 3 shows a comparison of measured and modelpredicted pool sizes of ammonium and nitrite/nitrate. Generally, the changes in total pool size of DIN (i.e. predominantly the unlabelled fraction) are predicted well by the model, with 

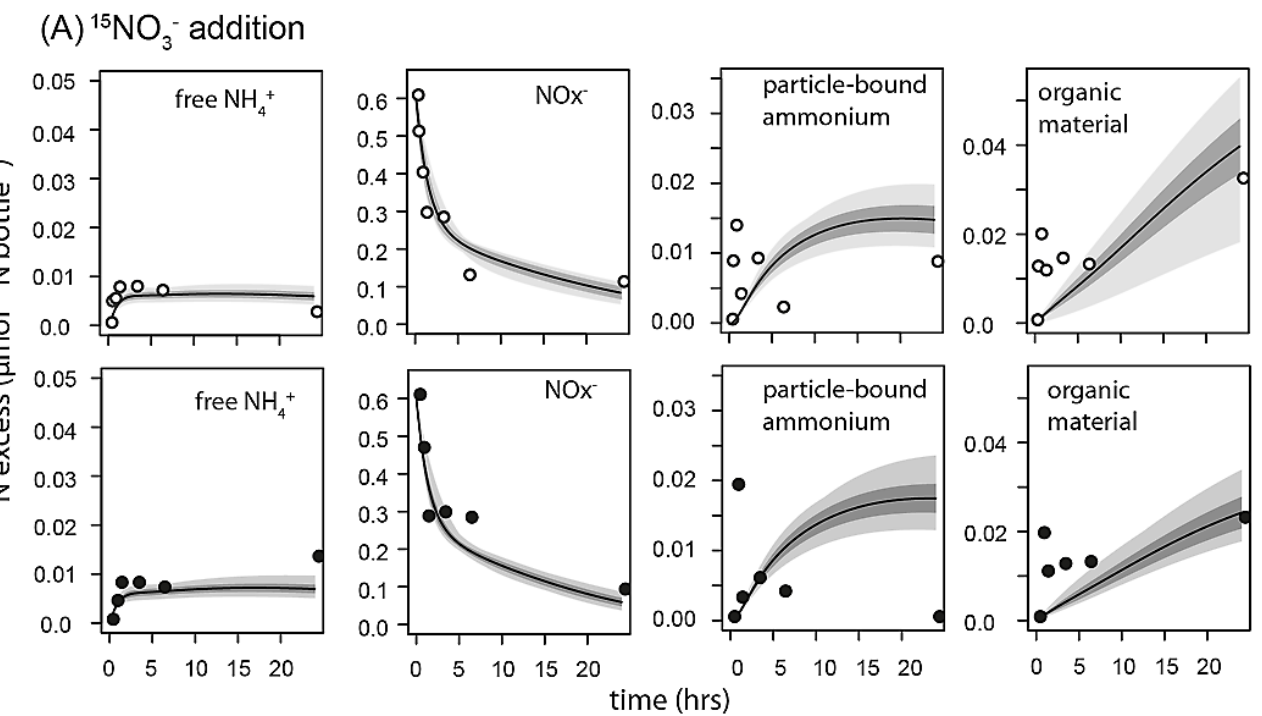

(B) ${ }^{15} \mathrm{NH}_{4}^{+}$addition
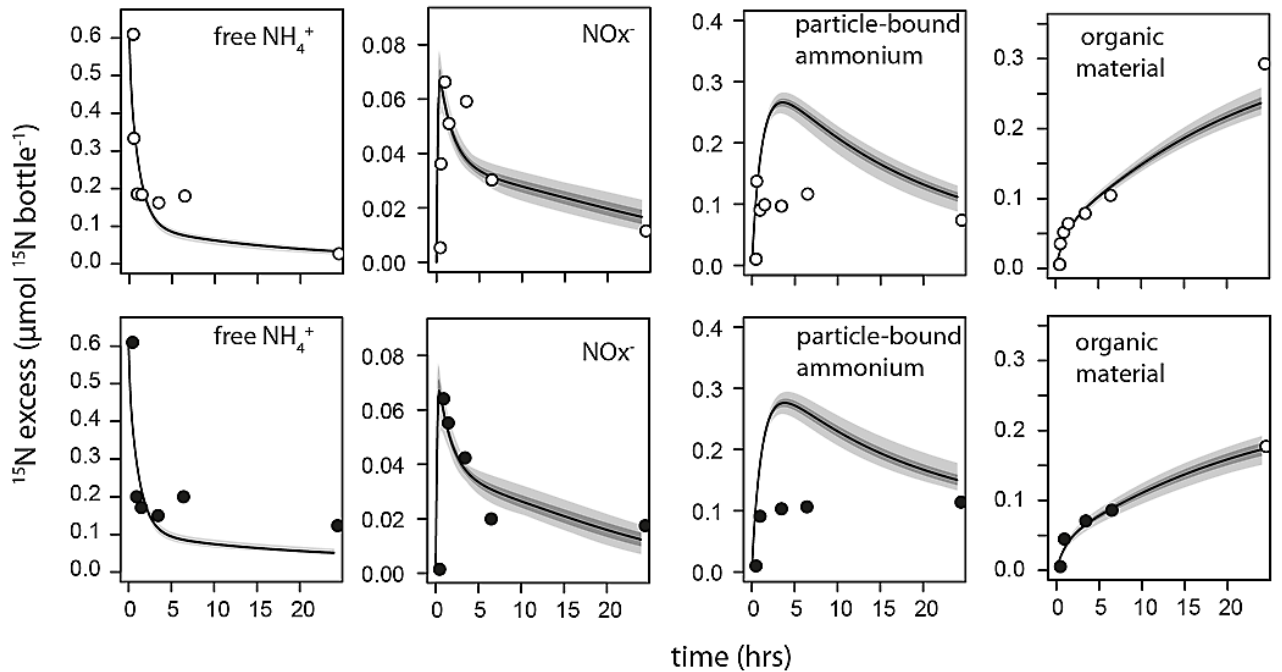

Fig. 4. Measured pools of ${ }^{15} \mathrm{~N}$ for ${ }^{15} \mathrm{~N}$-nitrate additions (A) and ${ }^{15} \mathrm{~N}$-ammonium additions (B) in dark (filled circles) and light (open circles). Solid lines and shading indicate model fits. Dark shaded areas represent one standard deviation; light shading indicates minimum and maximum values. Note different scales of y-axes.

ammonium concentrations dropping initially and then rising in the dark incubations, whereas they dropped in the light incubations (Fig. 3). For total ${ }^{15} \mathrm{NO}_{3}^{-}$concentration, the model predicts an initial rise in concentration, followed by a decrease towards the end of the incubation, with no significant differences in light and dark incubations, which is in accordance with the data. This suggests that the model assumptions are correct and provide valuable estimates not only of DIN pool sizes, but also of process rates of assimilatory and dissimilatory turnover.

For both nitrogen species, ammonium and nitrate, data were generally well described by the model (Figs. 3 and 4). The only exception is the prediction of the ${ }^{15} \mathrm{NH}_{4}^{+}$distribution in the ${ }^{15} \mathrm{~N}$-ammonium incubations: The model overesti- mates particle-bound $\mathrm{N}$ in ${ }^{15} \mathrm{NH}_{4}^{+}$incubations while underestimating it in ${ }^{15} \mathrm{NO}_{3}^{-}$additions (Fig. 4).

\subsection{Process rates - model results}

Figure 6 gives an overview of the model-derived process rates for the light and dark incubations. Model results for ${ }^{15} \mathrm{~N}$ ammonium and nitrate additions are comparable and are thus not discussed separately. Due to the addition of unlabelled substrates in the different incubations, total initial nutrient concentrations are identical; thus the same should apply to process rates. Generally, there is a pronounced difference in process rates between the first hours of the experiment versus 


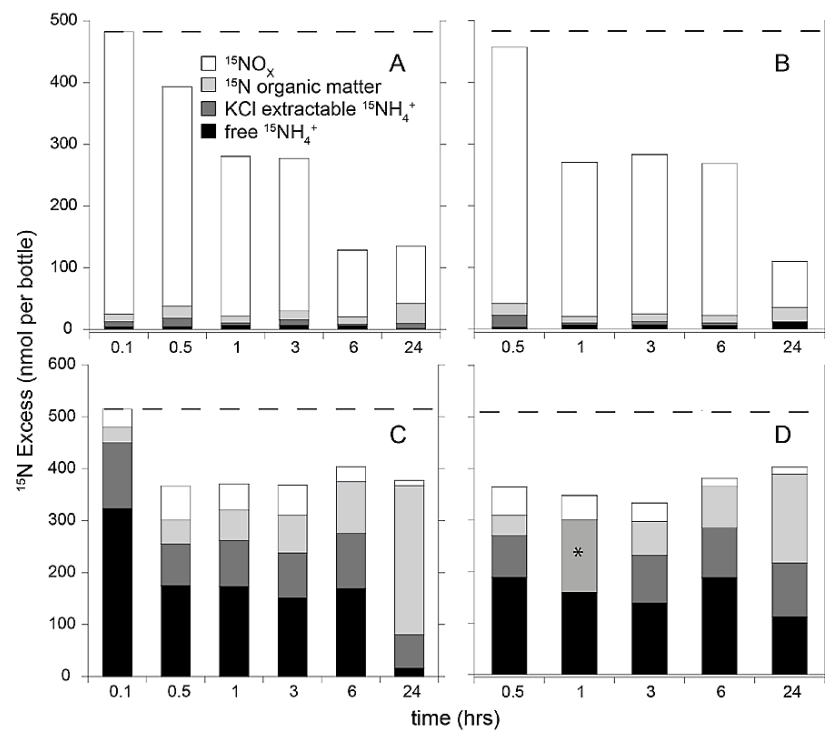

Fig. 5. Relative distribution of labelled $\mathrm{N}$ in different pools of nitrogen. (A) ${ }^{15} \mathrm{~N}$-nitrate addition in light and (B) dark; (C) ${ }^{15} \mathrm{~N}$ ammonium addition in light and (D) in dark. Asterisk in plot (D): sediment-bound ammonium and organic matter were not determined separately. The amount of the pool "missing label" was calculated by difference in comparison to the initial label addition, indicated by the dashed line (see text for details).

those for the 6-24 h period, which often reduce to but a fraction of the initial rate (Fig. 6).

In both incubations, assimilation of ammonium clearly outweighed assimilatory nitrate uptake. Initial ammonium uptake rates were as high as $0.8 \mu \mathrm{mol}$ per bottle $\mathrm{h}^{-1}$, whereas nitrate uptake occurred at a fraction of this rate, $\sim 0.02 \mu \mathrm{mol}$ per bottle $\mathrm{h}^{-1}$ (Fig. 6). Overall uptake rates for nitrate and ammonium were higher in light than in dark incubations. Initial rates of light and dark uptake were comparable, but there was a marked decrease in dark process rates. Ammonium uptake slowed down to about $75 \%$ of the initial rate, whereas nitrate uptake decreased gradually, approaching zero after 24 h. (Fig. 6).

Regarding dissimilative processing, the model reveals only few differences between light and dark incubations. In both setups, nitrification is most pronounced after mixing at the beginning of the incubation, with initial rates of more than $5 \mu \mathrm{mol} \mathrm{h}{ }^{-1}$ bottle $^{-1}$, which decrease to lower, but still substantial, turnover rates of $\mu \mathrm{molh}^{-1}$ over the course of the experiment. It was not possible to make a reliable distinction between $\mathrm{N}_{2}$ production by denitrification versus anammox; therefore, these two processes are presented as their sum. Gross $\mathrm{N}_{2}$ production is remarkable, with maximal rates approaching $1 \mu \mathrm{mol}$ per bottle $\mathrm{h}^{-1}$, levelling off to $\sim 0.25 \mu \mathrm{mol} \mathrm{h}^{-1}$ (Fig. 6). DNRA, however, was quantitatively less important, with rates $>0.1 \mu \mathrm{mol} \mathrm{h}^{-1}$ only within the first few hours of the incubation.
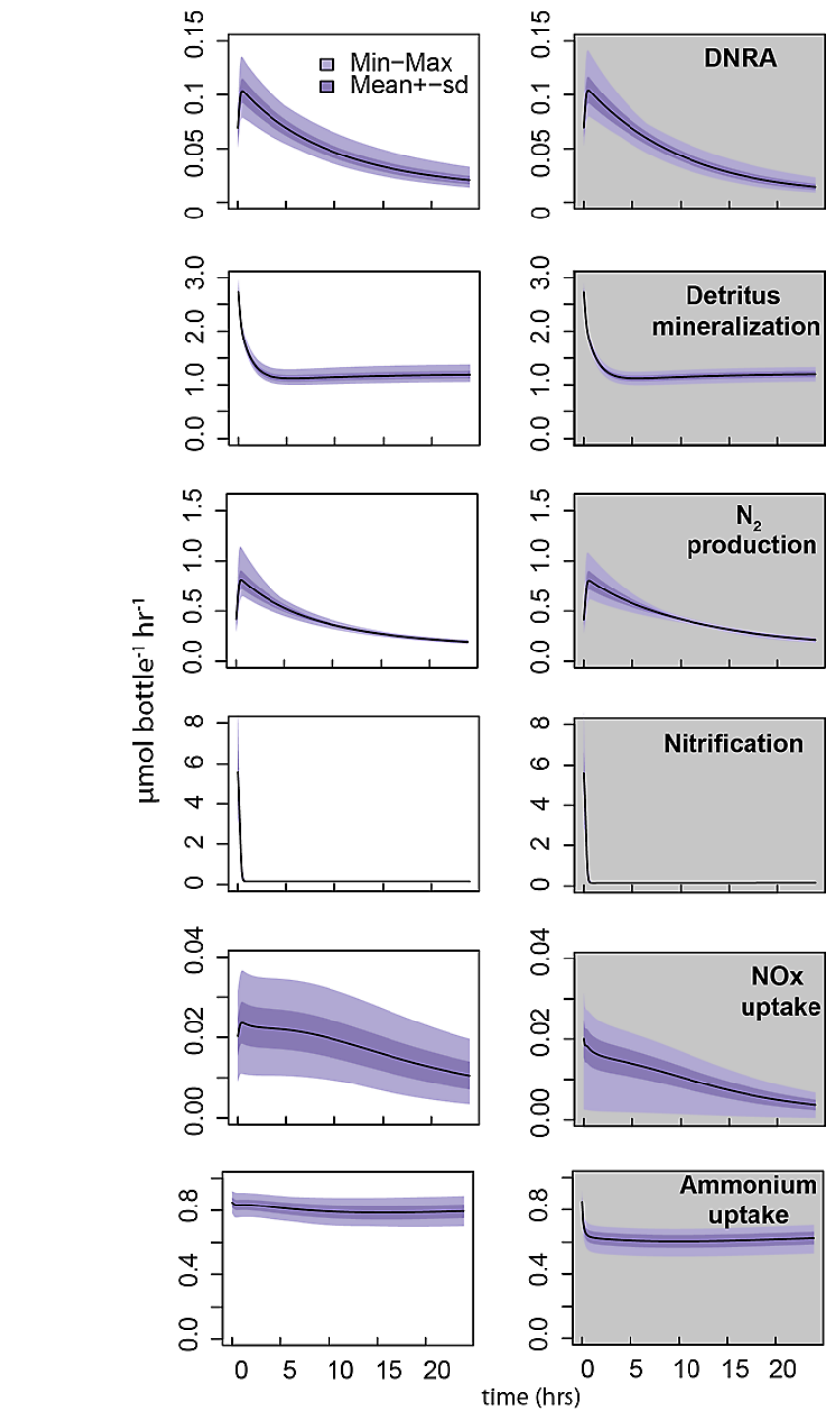

Fig. 6. Process rates derived from model. Left: rates in light, right side: rates in dark incubations.

\section{Discussion}

The evaluation of experimental data provides a good overview of the relative importance of various turnover mechanisms in the sediment incubations, and the comparison of these estimates with the model-derived process rates brings up interesting questions on the controlling mechanisms. In what follows, we will first discuss the process rates that are derived from model and experimental data, distinguishing between the initial phase of the experiment, when process rates were triggered by physical disturbance, and the second phase, when biogeochemical gradients reestablished, and process rates returned to a new steady state. Furthermore, we will assess the influence of benthic microalgae and specify the added value and insights 
regarding process rates that we gained from the modelling approach.

\subsection{The fate of ammonium}

At steady state, the major share of ammonium is turned over via assimilatory pathways, whereas nitrification seems to play a subordinate role. Illumination increased ammonium uptake by about $25 \%$, suggesting a significant contribution of BMA to total sedimentary ammonium uptake. Overall, assimilatory processes clearly prevail for ammonium turnover; 56 and $34 \%$ of the added label were recovered in the organic matter fraction in light and dark, respectively. In comparison, nitrification appears to be only relevant in the initial phase of the experiment. This is consistent with findings by Blackburn and Henriksen (1983), who investigated nitrogen fluxes in Danish sediments and found that largest fractions of ammonium were either assimilated or bound in the sediments, whereas nitrification was of subordinate role.

However, during the initial incubation phase, i.e. conditions following a sediment disturbance event, we found a clear transfer of label to the $\mathrm{NO}_{3}^{-}$pool (Fig. 4b) and accordingly high initial nitrification rates of $\sim 5 \mathrm{nmol} \mathrm{bottle}^{-1} \mathrm{~h}^{-1}$ (Fig. 6). After this, nitrification rates dwindled to a steady state of $0.16 \mu \mathrm{mol}$ bottle $\mathrm{e}^{-1} \mathrm{~h}^{-1}$. This decrease was swift and likely linked to oxygen limitation. During slurry preparation, oxygen was mixed into the sediment, and all preformed biogeochemical gradients were disrupted. Nitrification could thus proceed at a high rate until oxygen was depleted, after which it became limited by oxygen diffusion into the sediment.

Another candidate sink for ammonium is the anammox reaction. We did not measure the production of labelled $\mathrm{N}_{2}$ in the slurries and can thus not distinguish between denitrification and anammox, but it seems unlikely that anammox will play a significant role in a shallow, tidal, i.e. dynamic, environment like the tidal flat, because anammox bacteria are slow-growing and thus usually favoured by stable environmental conditions (Jensen et al., 2009). Denitrification, the alternative source for dinitrogen, appears to play a more important role, removing large amounts of nitrate in the incubation assay.

\subsection{The fate of nitrate}

There was little assimilation of nitrate into organic matter, and light conditions had only little influence on net nitrate uptake (Figs. 6 and 7). Rates for assimilation of nitrate were negligible in comparison to those for ammonium or to $\mathrm{N}_{2}$ production and had no significant effect on nutrient concentrations or label appearance in organic material. Overall, it appears that nitrate was almost exclusively subject to dissimilatory turnover (Fig. 6).

Dissimilatory processing of nitrate (i.e. denitrification or DNRA) decreased rapidly within the first hours of the incu- bation. Nitrate turnover was mostly coupled to a transport into the "missing label" pool (Fig. 5), which is consistent with the high rates of $\mathrm{N}_{2}$ production (Fig. 6). After a peak in $\mathrm{N}_{2}$ production rates at the beginning of the experiment, rates dropped significantly, approaching a stable level after 20 to $24 \mathrm{~h}$. These $\mathrm{N}_{2}$ production rates were apparently controlled by the availability of easily degradable organic matter. Denitrification depends on the availability of readily available electron acceptors (Pfenning and McMahon, 1997) as they are present in the labile detritus fraction. The concentration of this labile fraction was high at the beginning of the experiment, fuelling high denitrification rates, and decreased during the experiment. A further kinetic control on denitrification is exerted by the diffusion of nitrate into the denitrification zone: as the nitrate concentration in the homogenized sediment decreases with the establishment of stable biogeochemical gradients, less and less nitrate will find its way into the active denitrifying zone in the sediment, with rates consequently levelling off towards the end of the incubation.

Other potential dissimilatory processes like DNRA appeared to be of minor importance. The model approach revealed that initial DNRA rates were reasonably high $\left(\sim 0.1 \mu \mathrm{mol}\right.$ bottle $\left.\mathrm{e}^{-1} \mathrm{~h}^{-1}\right)$, but like denitrification rates, they decreased over the course of the experiment and resulted in little net production of labelled ammonium. Contrastingly, Porubsky et al. (2009) investigated tidal flats in South Carolina and Georgia, USA, and found that DNRA was significant and in direct competition with denitrification in sediments. They argue that DNRA appears to be stimulated and favoured over denitrification at temperatures above $20^{\circ} \mathrm{C}$. While we used a moderately high temperature of $17^{\circ} \mathrm{C}$, it seems plausible that bacterial communities are adapted to lower temperatures at our study site. This apparently resulted in little quantitative importance of DNRA in our experiment in comparison to the competing process, denitrification, regardless of light conditions or BMA activity.

\subsection{The balance between assimilatory versus dissimilatory processes}

The primary goal of this study was to evaluate the balance between assimilative and dissimilative nitrogen cycling processes in a tidal mudflat sediment exposed to different light levels and repetitive resuspension events. We found that this balance is governed not only by presence or absence of light, but just as well by physical disturbance. In the initial phase of the incubation, dissimilative processes clearly prevail, with nitrification and denitrification reaching maximum rates. As the experiment proceeds, process rates level off and approach a steady state, indicating the re-establishment of biogeochemical gradients in the sediment (cf. Risgaard-Petersen et al., 2004).

But how does this peak activity compare to a natural system? The most evident analogy to sediment mixing in our experiment is sediment reworking due to bioturbation and, 
especially important in a tidally influenced system like the Scheldt estuary, due to tidal forcing. Such mixing can lead to disruption of preformed gradients in the sediment, and to burial of benthic microalgae (Kamp et al., 2011). Trimmer et al. (2005) investigated the impact of mixing due to bottom trawling and tides. Similar to the rapid recovery in our experiment, they found that sedimentary processes rapidly return to their former status. However, the most pronounced factor governing the assimilatory/dissimilatory balance obviously is this physical disturbance, be it in tidal sediments in the estuary or in our experimental assay.

After this initial experimental phase, when sediments return to their former state, we were aiming to estimate the microalgal contribution by comparing process rates in light versus dark sediment incubations. A limitation to this approach is that a certain portion of algal $\mathrm{N}$ uptake can continue under dark conditions. Evrard et al. (2008) found that dark nitrate uptake was decoupled from carbon assimilation and approached $75 \%$ of the light uptake. For ammonium, dark uptake rates can also approach $20 \%$ of those found in light (Thornton et al., 1999). However, the lack of light clearly reduced algal uptake and provides us with a minimum estimate of their impact in this sediment.

The most important result from our study is that ammonium was predominantly assimilated in the sediment regardless of the light conditions (see previous section). Dissimilatory processes like nitrification are primarily of importance in the initial phase of the experiment. In contrast, assimilation is of subordinate role for nitrate or nitrite. At steady state an average of $6 \%$ of the added ${ }^{15} \mathrm{NO}_{3}^{-}$entered the organic matter pool, while dissimilatory processing of nitrate, mainly as denitrification, clearly prevailed

What are the implications of our results for nutrient turnover in the Scheldt estuary? Today, the main input of reactive nitrogen to the Scheldt estuary is in the form of nitrate; ammonium comprises $<10 \%$ of the total reactive nitrogen load (e.g. Soetaert et al., 2006). Our results indicate that nitrate will mainly be removed via denitrification in the estuary, and that this removal is likely stimulated on short time scales by sediment mixing due to tidal forcing, wave activity and bioturbation.

Overall, while net nitrate retention in the Scheldt estuary has decreased, our results indicate that perturbations of the sediment, like we deliberately induced by shaking the slurries, have a very high short-term impact on the $\mathrm{N}$-cycle. The natural equivalent of this manual shaking is bioturbation and wave- or tide-induced mixing of sediment. Particularly in the outer tidal flat system, the estuary is heavily influenced by tidal forcing (Vanderborght et al., 2007) and waves (Callaghan et al., 2010). Our results suggest that these processes can trigger dissimilatory pathways like denitrification and nitrification for a short time period, and a coupling of these two processes can lead to substantial nutrient removal (Laursen and Seitzinger, 2002). After re-establishment of stable biogeochemical gradients, other factors, like the oc- currence of benthic microalgae, apparently gain in importance. These interactions of physical processing and biological turnover rates should be kept in mind as natural process rates can be altered in disturbed systems due to human interactions not only in the Scheldt estuary, but also in other shallow coastal regions.

\subsection{The role of benthic microalgae}

The nutrient and label distribution in the equilibrated incubations points towards some marked differences between light and dark conditions, providing clear evidence that the activity of benthic microalgae had an impact on sedimentary $\mathrm{N}$ cycling in tidal sediments from the Scheldt estuary.

The most striking difference between light and dark incubations was the change in ammonium assimilation rates. Within the first hour of the incubation, the dark assimilation rate dropped to $\sim 75 \%$ of that in light (Fig. 6). Thus, BMA seem to have been responsible for at least a quarter of the overall uptake rate in the light. Interestingly, this was sufficient to convert the sediments from being a net ammonium source (dark incubations, cf. Figs. 3 and 6) into being a net sink for reactive nitrogen.

Besides this obvious effect on ammonium assimilation, this shows that BMA compete with the bacterial community - including nitrifiers - for ammonium. This can lead to reduced nitrification and a lower flux of nitrate to denitrification. Coupled nitrification/denitrification often represents a significant share of total denitrification and is reduced when assimilation by MPB is increased. Thornton et al. (2007) explored sedimentary nutrient fluxes in the Colne estuary and found that denitrification was governed by light conditions, with significantly higher rates during dark phases. We did not see such inhibition in our experiment; it is apparently overcome by other factors favouring denitrification. A candidate mechanism is the exudation of organic matter during illumination (Cook et al., 2009): Denitrifiers rely not only on nitrate but also on organic substrates, and, accordingly, easily accessible sources of organic matter can potentially enhance rates of denitrification.

The combined effect of the observed higher assimilation of ammonium and continuous nitrification/denitrification in the light resulted in a much stronger sequestration of $\mathrm{NH}_{4}^{+}$ in the experiment (cf. Fig. 3) in light. While the sediments still were net total DIN sinks due to strong denitrification in both light and dark, they shifted from being a net sink for ammonium under illuminated conditions to being a net ammonium source in the dark. Such net efflux of ammonium can be due to DNRA in some environments (Fulweiler et al., 2008; Gardner et al., 2006), but the role of DNRA appears to be limited in intertidal Scheldt estuary sediments (see above). We presume that, in this case, the shift to net sedimentary ammonium production in the dark is due to dwindling BMA ammonium uptake when light is limiting, not to increasing DNRA. 


\subsection{Selective removal of ${ }^{15} \mathrm{~N}$ ?}

The model was essential in unravelling our ${ }^{15} \mathrm{~N}$ results and translating these into process rates for the complex benthic $\mathrm{N}$-cycle. In some cases, the initial model assumptions and the experimental data were not entirely consistent and modification of the original conceptual model was required in order for the model to be able to reproduce the experimental results. The most profound difference was that the original model was unable to reproduce the initial decrease in the labelling percentage of nitrate. This offset between data and model could be overcome by inclusion of a process that selectively removed ${ }^{15} \mathrm{NO}_{3}^{-}$from the total dissolved $\mathrm{NO}_{3}^{-}$ pool (see materials and methods section). We can only speculate on what process accounted for this selective removal, but one probable mechanism is intracellular nitrate storage by diatoms. Diatoms can represent a substantial part of the BMA in the sediment (Sundback et al., 2011) and dominate the BMA community in our study area (Veuger and van Oevelen, 2011). They are known to store nitrate internally in up to millimolar concentrations (Dortch et al., 1984; Pettersson and Sahlsten, 1990; Flynn et al., 2002), thus playing an important role in marine nutrient cycling. Interestingly, it has long been hypothesized that this uptake of nitrate by diatom cells is at least party regulated via diffusion (Lomas and Glibert, 1999; Serra et al., 1978). Unlike most other uptake mechanisms, diffusion will, in a label addition experiment, differentially act on the two isotope species. Unlike active transport mechanisms, a diffusion-driven uptake will preferentially act on the newly added ${ }^{15} \mathrm{~N}$ until an equilibrium is achieved. Consequently, ${ }^{15} \mathrm{~N}$ will initially diffuse into the cells until equilibrium with ${ }^{15} \mathrm{~N}$ in the environment is achieved. This can explain the rapid decrease in labelled ${ }^{15} \mathrm{NO}_{3}^{-}$in the dissolved pool in our experiment (Fig. 4a). This pool of internally stored nitrate is not captured in the pool of ${ }^{15} \mathrm{~N}$ in organic matter because the latter involves particulate organic material (i.e. biomass) while intracellular dissolved $\mathrm{NO}_{3}^{-}$was likely removed by the $\mathrm{KCl}$ extraction.

Surprisingly, a similar phenomenon can be seen for the removal of ${ }^{15} \mathrm{NH}_{4}^{+}$. There appears to be a similar process acting preferentially on the heavier ammonium isotope, but it is not easy to infer which process might be responsible for this behaviour. Some authors (Lomas and Glibert, 2000; Baek et al., 2008) observed internal storage of excess ammonium in flagellates, but it is not clear whether these mechanisms play a role in our experiment, where sedimentary turnover governs process rates. Furthermore, there is no proof of diffusion-driven uptake of ammonium by these organisms, so the mechanistic basis of this ammonium uptake remains somewhat speculative.

Barring uncertainty about the precise processes involved for ammonium, these selective uptake processes are only revealed by the modelling approach used in this study in addition to the experimental data. This shows that such a combined approach provides valuable additional information on the processes under study - in this case the presence and relevance of diatoms in coastal nitrogen cycling. Consequently, even though our data do not allow the precise identification and quantification of the two mechanisms that are responsible for the selective removal of labelled ammonium or nitrate, our results clearly demonstrate its relevance for interpretation of the stable isotope tracer results and quantification of resulting process rates. This highlights the added value of the combined approach of modelling and experimental data, which allowed us not only to determine process rates for our setup, but also revealed these - unexpected - selective removal mechanisms that we would have been unable to detect using the experimental data alone. Yet, such selective processes have a significant impact on the pool size of labelled compounds, which are the basis for most calculations of process rates. Accordingly, disregarding these processes can obviously lead to erroneous process rate estimations.

\section{Conclusions}

The outcome of this study is two-fold: First, we find that the balance of assimilative/dissimilative processes is altered by sediment homogenization, enhancing dissimilatory processes and most probably triggering coupled nitrification/denitrification. This means that, even though nitrification rates on the long term are low, such sediments have a high potential for nitrification which is expressed if they are physically perturbed. In the field, such perturbations are expected by fauna or currents, suggesting that assimilation or dissimilation can be driven to a large extent by external physical or biotic forcing, with the entire system being capable of rapid shifts following environmental changes.

After a short equilibration time in our experiment, results then indicate that the balance between assimilation and dissimilation in the investigated sediment differed depending on the nitrogen source. Ammonium was primarily assimilated, while nitrate was utilized almost exclusively in dissimilatory processes like denitrification, with only little evidence of other dissimilatory processes like nitrification or DNRA. Benthic microalgae apparently did not stimulate dissimilatory pathways in our sediment, but had a substantial impact on sedimentary ammonium assimilation: When BMA ammonium assimilation ceased, sediments in our experiment switched from being a net sink for ammonium to being a net source.

Second, our combined experimental and modelling approach highlights the importance of pathways that selectively remove labelled ammonium, as well as nitrate. We can merely speculate on the precise mechanisms involved, but there is further need to study the relevance of these processes in natural environments. 


\section{Supplementary material related to this article is available online at: http://www.biogeosciences.net/9/ 4059/2012/bg-9-4059-2012-supplement.pdf.}

Acknowledgements. We would like to thank Pieter van Rijswijk, Marco Houtekamer and Peter van Breugel, for their help with laboratory work. K. D, A. M. and B. V. were financially supported by the Netherlands Organization for scientific research (K. D. and B. V.: Pionier, project no. 833.02.2002, and A. M.: NICYCLE, project no. 839.08.334). B. V. received additional funding by the Darwin Center for Biogeology (project no. 142.16.1052).

Edited by: G. Herndl

\section{References}

An, S. and Joye, S. B.: Enhancement of coupled nitrificationdenitrification by benthic photosynthesis in shallow estuarine sediments, Limnol. Oceanogr., 46, 62-74, 2001.

Andersson, M. G. I., Brion, N., and Middelburg, J. J.: Comparison of nitrifier activity versus growth in the Scheldt estuary - a turbid, tidal estuary in northern Europe, Aquatic Microb. Ecol., 42, 149158, 2006a.

Andersson, M. G. I., van Rijswijk, P., and Middelburg, J. J.: Uptake of dissolved inorganic nitrogen, urea and amino acids in the Scheldt estuary: comparison of organic carbon and nitrogen uptake, Aquat. Microb. Ecol., 44, 303-315, 2006b.

Baek, S. H., Shimode, S., Han, M. S., and Kikuchi, T.: Growth of dinoflagellates, Ceratium furca and Ceratium fusus in Sagami Bay, Japan: The role of nutrients, Harmful Algae, 7, 729-739, doi:10.1016/j.hal.2008.02.007, 2008.

Blackburn, T. H.: Method for measuring rates of $\mathrm{NH}_{4}^{+}$turnover in anoxic marine sediments, using a ${ }^{15} \mathrm{~N}^{-\mathrm{NH}_{4}^{+}}$dilution technique, Appl. Environ. Microb., 37, 760-765, 1979.

Blackburn, T. H. and Henriksen, K.: Nitrogen cycling in different types of sediments from Danish waters, Limnol. Oceanogr., 28, 477-493, 1983.

Callaghan, D. P., Bouma, T. J., Klaassen, P., van der Wal, D., Stive, M. J. F., and Herman, P. M. J.: Hydrodynamic forcing on salt-marsh development: Distinguishing the relative importance of waves and tidal flows, Estuar. Coast. Shelf S., 89, 73-88, doi:10.1016/j.ecss.2010.05.013, 2010.

Chen, M. S., Wartel, S., Van Eck, B., and Van Maldegem, D.: Suspended matter in the Scheldt estuary, Hydrobiologia, 540, 79104, doi:10.1007/s10750-004-7122-y, 2005.

Cook, P. L. M., Van Oevelen, D., Soetaert, K., and Middelburg, J. J.: Carbon and nitrogen cycling on intertidal mudflats of a temperate Australian estuary, IV. Inverse model analysis and synthesis, Mar. Ecol.-Prog. Ser., 394, 35-48, 2009.

Dähnke, K., Emeis, K., Johannsen, A., and Nagel, B.: Stable isotope composition and turnover of nitrate in the German Bight, Mar. Ecol.-Prog. Ser., 408, 7-18, 2010.

Dalsgaard, T. and Thamdrup, B.: Factors controlling anaerobic ammonium oxidation with nitrite in marine sediments, Appl. Environ. Microb., 68, 3802-3808, 2002.
Dalsgaard, T., Thamdrup, B., and Canfield, D. E.: Anaerobic ammonium oxidation (anammox) in the marine environment, Res. Microbiol., 156, 457-464, 2005.

Deek, A., Emeis, K., and van Beusekom, J.: Nitrogen removal in coastal sediments of the German Wadden Sea, Biogeochemistry, 1-17, doi:10.1007/s10533-011-9611-1, 2011.

Dortch, Q., Clayton, J. R., Thoresen, S. S., and Ahmed, S. I.: Species Differences in accumulation of nitrogen pools in phytoplankton, Mar. Biol., 81, 237-250, 1984.

Evrard, V., Cook, P. L. M., Veuger, B., Huettel, M., and Middelburg, J. J.: Tracing carbon and nitrogen incorporation and pathways in the microbial community of a photic subtidal sand, Aquat. Microb. Ecol., 53, 257-269, 2008.

Flynn, K. J., Clark, D. R., and Owens, N. J. P.: Modelling suggests that optimization of dark nitrogen-assimilation need not be a critical selective feature in phytoplankton, New Phytol., 155, 109119, doi:10.1046/j.1469-8137.2002.00436.x, 2002.

Fulweiler, R. W., Nixon, S. W., Buckley, B. A., and Granger, S. L.: Net Sediment $\mathrm{N}_{2}$ Fluxes in a Coastal Marine SystemExperimental Manipulations and a Conceptual Model, Ecosystems, 11, 1168-1180, doi:10.1007/s10021-008-9187-3, 2008.

Gardner, W. S., McCarthy, M. J., An, S., Sobolev, D., Sell, K. S., and Brock, D.: Nitrogen fixation and dissimilatory nitrate reduction to ammonium (DNRA) support nitrogen dynamics in Texas estuaries, Limnol. Oceanogr., 51, 558-568, 2006.

Grasshoff, K. and Anderson, L. G.: Methods of seawater analysis, Wiley-VCH, 1999.

Heip, C. H. R., Goosen, N. K., Herman, P. M. J., Kromkamp, J., Middelburg, J. J., and Soetaert, K.: Production and consumption of biological particles in temperate tidal estuaries, in: Oceanography and Marine Biology - an Annual Review, Vol. 33, Oceanography and Marine Biology, UCL Press Ltd., London, 1-149, 1995.

Holmes, R. M., McClelland, J. W., Sigman, D. M., Fry, B., and Peterson, B. J.: Measuring ${ }^{15} \mathrm{~N}-\mathrm{NH}_{4}^{+}$in marine, estuarine and fresh waters: An adaptation of the ammonia diffusion method for samples with low ammonium concentrations, Mar. Chem., 60, 235-243, 1998.

Holstein, J. M. and Wirtz, K. W.: Sensitivity analysis of nitrogen and carbon cycling in marine sediments, Estuar. Coast. Shelf S., 82, 632-644, doi:10.1016/j.ecss.2009.02.008, 2009.

Jensen, M. M., Petersen, J., Dalsgaard, T., and Thamdrup, B.: Pathways, rates, and regulation of $\mathrm{N}_{2}$ production in the chemocline of an anoxic basin, Mariager Fjord, Denmark, Mar. Chem., 113, 102-113, doi:10.1016/j.marchem.2009.01.002, 2009.

Jones, M. N.: Nitrate reduction by shaking with cadmium: Alternative to cadmium columns, Water Res., 18, 643-646, 1984.

Kamp, A., de Beer, D., Nitsch, J. L., and Stief, P.: Diatoms respire nitrate to survive dark and anoxic conditions, P. Natl. Acad. Sci. USA, 108, 5649-5654, 2011.

Laursen, A. E. and Seitzinger, S. P.: Measurement of denitrification in rivers: an integrated, whole reach approach, Hydrobiologia, 485, 67-81, 2002.

Lipschultz, F., Wofsy, S. C., and L. E. Fox, L. E.: NitrogenMetabolism of the eutrophic Delaware River Ecosystem, Limnol Oceanogr., 31, 701-716, 1986.

Lomas, M. W. and Glibert, P. M.: Temperature regulation of nitrate uptake: A novel hypothesis about nitrate uptake and reduction in cool-water diatoms, Limnol. Oceanogr., 44, 556-572, 1999. 
Lomas, M. W. and Glibert, P. M.: Comparisons of nitrate uptake, storage, and reduction in marine diatoms and flagellates, J. Phycol., 36, 903-913, 2000.

Middelboe, M., Kroer, N., Jorgensen, N. O. G., and Pakulski, D.: Influence of sediment on pelagic carbon and nitrogen turnover in a shallow Danish estuary, Aquat. Microb. Ecol., 14, 81-90, 1998.

Pettersson, K. and Sahlsten, E.: Diel patterns of combined nitrogen uptake and intracellular storage of nitrate by phytoplankton in the open Skagerrak, J. Exp. Mar. Biol. Ecol., 138, 167-182, 1990.

Pfenning, K. S. and McMahon, P. B.: Effect of nitrate, organic carbon, and temperature on potential denitrification rates in nitrate-rich riverbed sediments, J. Hydrol., 187, 283-295, doi:10.1016/s0022-1694(96)03052-1, 1997.

Piehler, M. F., Currin, C. A., and Hall, N. S.: Estuarine intertidal sandflat benthic microalgal responses to in situ and mesocosm nitrogen additions, J. Exp. Mar. Biol. Ecol., 390, 99-105, 2010.

Porubsky, W. P., Weston, N. B., and Joye, S. B.: Benthic metabolism and the fate of dissolved inorganic nitrogen in intertidal sediments, Estuar. Coast. Shelf S., 83, 392-402, doi:10.1016/j.ecss.2009.04.012, 2009.

Preston, T., Zainal, K., Anderson, S., Bury, S. J., and Slater, C.: Isotope dilution analysis of combined nitrogen in natural waters, III. Nitrate and nitrite, Rapid Commun. Mass Sp., 12, 423-428, 1998.

Rich, J. J., Dale, O. R., Song, B., and Ward, B. B.: Anaerobic ammonium oxidation (Anammox) in Chesapeake Bay sediments, Microb. Ecol., 55, 311-320, 2008.

Risgaard-Petersen, N.: Coupled nitrification-denitrification in autotrophic and heterotrophic estuarine sediments: On the influence of benthic microalgae, Limnol. Oceanogr., 48, 93-105, 2003.

Risgaard-Petersen, N., Nicolaisen, M. H., Revsbech, N. P., and Lomstein, B. A.: Competition between ammonia-oxidizing bacteria and benthic microalgae, Appl. Environ. Microb., 70, 55285537, 2004.

Risgaard-Petersen, N., Meyer, R. L., and Revsbech, N. P.: Denitrification and anaerobic ammonium oxidation in sediments: effects of microphytobenthos and $\mathrm{NO}_{3}$, Aquat. Microb. Ecol., 40, 6776, 2005.

Serra, J. L., llama, M. J., and Cadenas, E.: Nitrate Utilization by the Diatom Skeletonema costatum, I. Kinetics of nitrate uptake, Plant Physiol., 62, 987-990, 1978.

Sigman, D. M., Altabet, M. A., Michener, R., McCorkle, D. C., Fry, B., and Holmes, R. M.: Natural abundance-level measurement of the nitrogen isotopic composition of oceanic nitrate: an adaptation of the ammonia diffusion method, Mar. Chem., 57, 227-242, 1997.

Soetaert, K., Middelburg, J. J., Heip, C., Meire, P., Van Damme, S., and Maris, T.: Long-term change in dissolved inorganic nutrients in the heterotrophic Scheldt estuary (Belgium, The Netherlands), Limnol. Oceanogr., 51, 409-423, 2006.
Sundback, K., Lindehoff, E., and Graneli, E.: Dissolved organic nitrogen: an important source of nitrogen for the microphytobenthos in sandy sediment, Aquatic Microb. Ecol., 63, 89-100, doi:10.3354/ame01479, 2011.

Thamdrup, B. and Dalsgaard, T.: Production of $\mathrm{N}_{2}$ through anaerobic ammonium oxidation coupled to nitrate reduction in marine sediments, Appl. Environ. Microb., 68, 1312-1318, 2002.

Thornton, D. C. O., Underwood, G. J. C., and D. B. Nedwell, D. B.: Effect of illumination and emersion period on the exchange of ammonium across the estuarine sediment-water interface, Mar. Ecol.-Prog. Ser., 184, 11-20, 1999.

Thornton, D. C. O., Dong, L. F., Underwood, G. J. C., and Nedwell, D. B.: Sediment-water inorganic nutrient exchange and nitrogen budgets in the Colne Estuary, UK, Mar. Ecol.-Prog. Ser., 337, 63-77, 2007.

Trimmer, M., Nicholls, J. C., and Deflandre, B.: Anaerobic Ammonium Oxidation Measured in Sediments along the Thames Estuary, United Kingdom, Appl. Environ. Microbiol., 69, 6447-6454, doi:10.1128/aem.69.11.6447-6454.2003, 2003.

Trimmer, M., Petersen, J., Sivyer, D. B., Mills, C., Young, E., and Parker, E. R.: Impact of long-term benthic trawl disturbance on sediment sorting and biogeochemistry in the southern North Sea, Mar. Ecol.-Prog. Ser., 298, 79-94, doi:10.3354/meps298079, 2005.

van Beusekom, J., Brockmann, U., Hesse, K., Hickel, W., Poremba, K., and Tillmann, U.: The importance of sediments in the transformation and turnover of nutrients and organic matter in the Wadden Sea and German Bight, Ocean Dynam., 51, 245-266, 1999.

Vanderborght, J. P., Folmer, I. M., Aguilera, D. R., Uhrenholdt, T., and Regnier, P.: Reactive-transport modelling of $\mathrm{C}, \mathrm{N}$, and $\mathrm{O}_{2}$ in a river-estuarine-coastal zone system: Application to the Scheldt estuary, Mar. Chem., 106, 92-110, doi:10.1016/j.marchem.2006.06.006, 2007.

Veuger, B. and van Oevelen, D.: Long-term pigment dynamics and diatom survival in dark sediment, Limnol. Oceanogr., 56, 10651074, 2011.

Veuger, B., Middelburg, J. J., Boschker, H. T. S., and Houtekamer, M.: Analysis of ${ }^{15} \mathrm{~N}$ incorporation into D-alanine: A new method for tracing nitrogen uptake by bacteria, Limnol. Oceanogr.Meth., 3, 230-240, 2005.

Ward, B. B.: Temporal variability in nitrification rates and related biogeochemical factors in Monterey Bay, California, USA, Mar. Ecol.-Prog. Ser., 292, 97-109, doi:10.3354/meps292097, 2005.

Widdows, J., Blauw, A., Heip, C. H. R., Herman, P. M. J., Lucas, C. H., Middelburg, J. J., Schmidt, S., Brinsley, M. D., Twisk, F., and Verbeek, H.: Role of physical and biological processes in sediment dynamics of a tidal flat in Westerschelde Estuary, SW Netherlands, Mar. Ecol.-Prog. Ser., 274, 41-56, doi:10.3354/meps274041, 2004. 